\title{
Plotino e o ceticismo
}

\author{
Mauricio Pagotto Marsola \\ UNIFESP/SP \\ mauriciomarsola@uol.com.br
}

resumo 0 que segue é apenas o conjunto de algumas hipóteses de trabalho a respeito da presença de argumentos céticos nas Enéadas, particularmente no tratado V 3 [49]. 0 ceticismo apresentase no interior de um variegado de argumentos dos quais Plotino se vale contra teses que ele pretende criticar. Tais teses dizem respeito: a) ao conhecimento sensível, toma do como fonte do conhe cimento verdade iro, cujo questio na mento leva Plotino a compreender que a verdade situa-se em outra instância que não a esfera do sensivel; b) à identida de ent re o Intelecto e seu conteúdo, no plano int eligivel; c) ao questio name nto da possibilida de de que o Intelecto divino, em seu sentido aristotélico, seja o princípio primeiro da realida de; d) à problemática da inefabilida de do Primeiro Princípio. Nossa estratégia será a de: a) abordarmos algumas hipóteses acerca da estrutura do intel igivel e da possibilida de do conhe cimento de si, identificandb quais são os usos plotinianos de tal estrutura e como ela pode ser mobilizada na crítica ao Intelecto, se tomado como princípio. Desse problema decorre b) a identificação da presença do ceticismo na questão da negatividade fundamental do Primeiro Princípio inefável, que denota a impossibilida de absoluta de introduzir qualquer relação de alterida de exteriorida de provindas de nossas afecções, em nosso discurso sobre o Uno. Tais referências ao ceticismo levam-nos a cons ide rar seu papel, como modus operandi, no int e rior da metodologia filosófica plotiniana. Nossa preocupação, portanto, é essencialmente metodológica.

palavras-chave Inefabilidade; dúvida cética; Intelecto; verdade; conhecimento de si

Para Bento Prado Jr.

(in memoriam).

Recebido em 12 de julho de 2007. Aceito em 03 de novembro de 2007.

doispontos, Curitiba, São Carlos, vol. 4, n. 2, p.247-273, outubro, 2007 


\section{8}

\section{Uma performance cética?}

1. Causa estranhamento ao leitor habituado aos esquemas tradicionais da História da Filosofia a constatação de referências céticas no interior das Enéadas.Tais esquemas classificatórios, como bem sabemos, desenham um quadro no qual a filosofia plotiniana, sob a égide do assim chamado Neoplatonismo, estaria ligada à preocupação dogmática de conservação de uma certa ortodoxia platônica ${ }^{1}$. De outro lado, ela é freqüentemente compreendida no quadro de um misticismo supra-noético, que abre as portas para um tipo de conhecimento extra-filosófico. Aliás, de uma perspectiva alheia a tais esquemas, mas não menos artificial, poderíamos igualmente fazer referência à divisão entre, de um lado, uma certa tradição crítica da Filosofia ocidental, preservada e definitivamente articulada pelo ceticismo, e, de outro lado, a uma certa tradição dogmática, ligada àquilo que poderia ser chamado de "filosofias do Absoluto" ou "filosofias do necessário". Dela fariam parte as filosofias platônica, ari stotélica e, par excellence, a plotiniana. Sem dúvida, não é sem dificuldade que podemos deixar de dar assentimento a afirmações como a de R. Arnou, que diz: "Plotino é um dogmático. O seu pensamento se exprime ordinariamente em sentenças peremptórias, em juízo definitivos. Não se trata de um conjunto de hipóteses que se propõe discutir, mas de uma doutrina que se impõe sob a base da intransigência da verdade" (ARNOU, 1967, p. 22 [grifo nosso]). Arnou afirma ainda que se trata de uma filosofia do necessário, confirmada pela onipresença da expressão "ex anankhés" " "por necessidade"; "necessariamente") ao longo dos textos. Logo, "Plotino duvida muito raramente" (ARNOU, 1967, p. 23).

2. Malgrado as afirmações categóricas de Arnou, sabemos que a identificação de elementos do pensamento cético nas Enéadas já aparece, em 1931, na edição clássica de $B$ réhier², na qual podemos constatar algumas referências a Sexto Empírico, notadamente em dois dos mais sutis, penetrantes e complexos tratados plotinianos: $\mathrm{V} 3$ [49] e $\mathrm{V} 5$ [32]. Além disso, ao se consultar o Index fontium da edição de Henry-Schwyzer, constata-se a referência ao $A$ dversus Mathematicos e às Hypotyposes em 30 passagens ao longo das Enéadas (Plotini opera [editio minor], vol. III, p. 367). Plotino não apenas mostra-se consciente da filosofia cética, mas ela é objeto de discussão, seja do ponto de vista 
refutatório, seja operando como um dos elementos que compõem a argumentação referente a temas como o conhecimento de si, a base sensível do conhecimento ou a inefabilidade do Princípio. Um exame do status quaestionis ${ }^{3}$ a esse respeito leva-nos à constatação de um número ainda reduzido de estudos, dada a importância da temática nos referidos tratados (como nota WALLIS, 1987, p. 912), bem como de sua possível extensão a outros textos das Enéadas.

Pode-se observar, inicialmente, que a própria performance de Plotino é similar, muitas vezes, àquele procedimento cético de mobilizar discursos filosóficos estabelecidos para criticar e desconstruir as teses que se tem em mira. Plotino, assim, emprega argumentos céticos contra os estóicos, epicuristas e gnósticos, mas retoma teses aristotélicas contra os céticos, como, por exemplo, no contexto do tratado 49, no exame da possibilidade de autoconhecimento no plano do Intelecto $(\text { Noûs })^{4}$. O mesmo Intelecto primeirode Aristóteles é, por sua vez, criticado, quando posto como candidato a Princípio Primeiro Tal performance pode ser compreendida como um recurso metodológico do qual o filósofo se vale, nunca abandonando sua pertença à família platônica ${ }^{5}$.Vale notar ainda, nesse contexto, que Plotino mobiliza argumentos de muitas procedências, em contextos díspares, conforme o adversário em questão (muitas vezes representado pelo interlocutor imaginário na diatribe). De acordo com as teses que estão sendo criticadas, os argumentos plotinianos assumem cores diversas. Portanto, jamais é ociosa a preocupação metodológica que considera que para cada quadro crítico é necessário notar a quem Plotino dirige seus argumentos. Isso é claro nos pontos centrais da crítica cética e da crítica a Aristóteles no tratado 49. Como veremos, quando Plotino critica os céticos a respeito da possibilidade de conhecimento de si, o Intelecto é tomado como unidade de si para consigo. Mas quando a compreensão aristotélica do Primeiro Motor como "intelecção da intelecção" (noêsis noêseôs) é visada, de modo que o Intelecto é visto como multiplicidade, sendo, pelo Princípio da Anterioridade do Simples, postulada a impossibilidade de que ele seja o Princípio Primeiro Desse modo, que tipo de dogmático, afinal, seria Plotino? 


\section{Identidade, alteridade e verdade no Intelecto.}

a) Do tema do erro e da falibilidade do conhecimento sensível ao conhecimento verdadeiro no Noûs.

3. Nos tratados contra os gnósticos ${ }^{6}$, Plotino critica a inserção, ainda que metafórica, do tema do erro e da negatividade maléfica no interior da própria constituição do mundo sensível. O mito gnóstico é o de um Demiurgo ignorante que se engana sobre o que produz, de modo que possamos conceber o mundo como um erro. Embora esse recurso gnóstico tenha a finalidade de explicação do mistério da efetividade do que é percebido como maléfico no mundo, em sua exegese Timeu, Plotino conclui, ao contrário, que o mundo é expressão do conhecimento adequado, relacionado à proporção geométrica, guardando traços do plano inteligível do qual provém. Tal conhecimento é possuído, em sua plenitude, no plano inteligível, pelo Intelecto (Nô̂s), cuja natureza os gnósticos são incapazes de apreender, d evido à maneira dicotômica e mutuamente excludente pela qual vêem a relação entre o sensível e o inteligível (cf.V 5 [32], 1-6; II 9 [33], 47-50). Essa preocupação crítica em relação aos gnósticos será um horizonte que Plotino não abandonará ao considerar a crítica cética com relação ao conhecimento sensível. De fato, quando consideramos uma perspectiva estritamente externalista ou sensualista, os argumentos céticos devem ser levados a sério e mesmo empregandos contra tais epistemologias. Esses argumentos auxiliam-nos no exercício crítico do conhecimento com relação à exterioridade dicotômica, típica da estrutura da percepção sensível. E é precisamente o pro blema da ambigüidade com relação à impossibilidade de alteridade e da exterioridade, no que diz respeito ao conhecimento inteligível, que permanecerá no horizonte plotiniano tanto nos tratados antignósticos (32 e 33) quanto, diretamente, no tratado 49. É necessário investigar como no Intelecto não pode haver erro, uma vez que não há relação de exterioridade, mas pensamento e pensado formam uma unidade, imediatamente presentes um ao outro, cuja verdade não carece de provas, pois permanece auto-evidente. Assim, o Intelecto é, em si e por si, tomado como alêtheia ${ }^{7}$. Será neste ponto que encontramos, segundo a ordem cronológica dos tratados em que aparecem os argumentos céticos, a estratégia de fazer uso de tais argumentos a fim de fundar um conhecimento intelectual independente da sensação ${ }^{8}$. 
Em V 5 [32], 1, ao questionar a possibilidade de que haja erro no Intelecto, Plotino rememora os argumentos céticos contra a pretensão daquelas teorias que postulam o conhecimento verdadeiro como provindo da sensação (particularmente a estóica e epicurista). Ora, a interrogação cética dirá que a sensação é um processo pelo qual nós adquirimos imagens "representando" objetos, sendo que não podemos, contra a "re presentação apreensiva" (kathalêptikê phantasía) estóica, estar seguros quanto à verdade dessas imagens. As imagens podem refletir aspectos de nossos órgãos sensoriais muito mais do que possibilitar uma "representação apreensiva", adequada, das coisas, trata-se apenas de uma "representação do que aparece" (phantasía). Recordando o célebre exemplo que já aparece em Platão9, o bloco perceptivo "vento frio" diz respeito à minha sensação, não ao que é o vento em si mesmo. Não podemos, portanto, verificar a ve rdade das imagens perceptivas, pois tal verificação dependeria, ela mesma, das imagens perceptivas. Não é senão de nossas afecções (pathê) que falamos ao nos referirmos às coisas. Retomaremos as implicações de tais argumentos céticos com relação ao conhecimento sensível quando tratarmos da possibilidade de interp retação da aplicação de tais argumentos no quadro das aporias relativas à inefabilidade do Uno. Que nos detenhamos, agora, na questão das dificuldades levantadas pelas objeções céticas com relação ao conhecimento de si, que permitem a Plotino abordar a natureza atual do Intelecto primeiro e sua estrutura.

EmV 5 [32], 12-15, o procedimento plotiniano é de remoção (aphaíresis) da base sensível do conhecimento verdadeiro. Encontramos aqui um paralelo estreito com Hypotyposes I, 12-20; II, 51, 72. No texto referido de V 5 é dito que os dados da sensação correspondem não à coisas perc ebidas, mas às afecções (pathê) que sobrevêm a nossos sentidos. Porém, o problema aparece quanto ao critério que temos para julgá-las: a sensação não pode ser candidata a critério, pois é parte do próprio processo perceptivo, de modo que recairíamos num círculo. Ou seja, a sensação jamais pode ser index sui. Como é dito em 15, 19: "Mesmo admitindo (sugkekhôrêménon) que as coisas que a sensação nos faz perceber (antilêpsis) são reais (hypokeiménois), o que é conhecido pelos sentidos não é senão uma imagem (eidôlon) ou espécie da coisa (prágmatos), e os sentidos não apreendem algo em si mesmo, ela permanece externa (éxô)" ${ }^{10}$. Não cabe 


\section{2}

comentar especificamente esse texto repleto de implicações epistemológicas nas limitadas dimensões deste trabalho. Mas vale notar que a percepção sensível não suprime a necessidade de questionar como é possível que o lógos instaure condições de conhecimento verdadeiro do que é exterior. Ora, ainda que apreendido sensivelmente, o algo que é apreendido permanece irredutivelmente exterioridade, indicada pelos termos eidôlon e éxô. O intelecto deverá voltar-se para si mesmo a fim de que possa colher dados do inteligível puro que forneçam índices para a consideração de um conhecimento que possa dizer a verdade. Tal conhecimento terá como index de verdade, como uma espécie de paradigma da verdade, o autoconhecimento provindo do Intelecto, ao mesmo tempo que a verdade propriamente dita, somente lá será identificada. No plano das experiências sensíveis e do conhecimento cotidiano, permanecemos envoltos num jogo de luz e sombras, uma vez que a sensação diz algo, mas como imagem e exterioridade com relação ao intelecto em si. Cabe notar ainda que, se assumirmos o ponto de vista da ordem cronológica dos tratados, o que é dito neste contexto do tratado 32 será retomado no tratado 49 , havendo um passo além na medida em que nesse último o conhecimento será abordado como autoconhecimento, identificado no Intelecto. As objeções céticas são, assim, simu ltaneamente consideradas, integradas e refutadas, conforme do tipo de conhecimento ao qual Plotino está se referindo e analisando.

4. Sabemos que Sexto Empírico dedica-se ao registro da análise de problemas relativos ao critério da verdade no livro II das Hypotyposes (caps. 3-9). Mas essencialmente, no tratado 49, o questionamento central de Plotino é saber como esse problema pode se colocar, dada aquela identidade entre conhecido e cognoscente que constitui a forma básica do Intelecto ${ }^{11}$. Tal crítica cética somente seria aplicável ao Intelecto caso ele fosse passível de divisão segundo a lógica da relação aqui implicada (ou seja, compreendido partes extra parte: uma parte que conhece e outra que é conhecida). Ora, no capítulo 5 (particularmente linhas 41-44) do referido tratado 49, Plotino argumenta contra a possibilidade de tal divisão, uma vez que isso implicaria a atribuição de uma relação entre todo e partes, não aplicável ao Intelecto. Fundamentalmente, o problema que se coloca aqui é o da relação de alteridade e de exterioridade entre cognoscente e conhecido. 
Após afirmar a unidade entre intelecção (nóêsis) e inteligível, em 5, 3032, Plotino afirma que o inteligível e a inteligência são idênticos ao ato da intelecção. "O intelecto, a intelecção e o inteligível são uma unidade (hèn háma panta éstai, nous, nóêsis, to noêtón)" (5, 43-44). Deste modo, "o intelecto é idêntico ao pensado (he nóêsis autou tò noêtòn)" $(5,44)$. Poderíamos dizer, neste sentido, que o Intelecto é index sui. Não se pode pensar em desdobramento e divisão de partes no Intelecto, tal como Sexto Empírico o concebe em sua crítica à noção de conhecimento de si no Adversus Mathematicos, VII, 310. Ora, no Intelecto há uma presença (parousía) imediata de todos os inteligíveis, constituindo-se como unidade entre Noûs, nóêsis e noêta, de modo que o conhecimento seria dado como auto-evidência ${ }^{12}$. O intelecto humano, ou seja, o noûs singular, guarda uma homologia estrutural com relação ao Intelecto-hipóstase (Noûs). Como lemos emV 5 [32], 2, 18-20:“(...) a verdade forma uma unidade não com algo outro, mas consigo mesma (ou symphônousa állô all'eautê), e não diz nada de outro além de si mesma (kaì oudèn par'autên állo légei), e é aquilo que diz e diz aquilo que ela é (alla hò légei, kai ésti, kai hó esti, touto kai légei)". Mas aqui nos deparamos com o problema, que igualmente não poderemos abordar profundamente no momento, da relação entre identidade e diferença, determinação e indeterminação no supra-sensível ${ }^{13}$. Podemos apenas apontar para um esquema possível: a) enquanto totalidade, o Intelecto é Ser e unidade: presença absoluta dos nóêta no Noûs, de modo que não há dualidade no modo de conhecimento supra-sensível que é a parousía, ou seja, a presença do Intelecto a si mesmo. A parousía será igualmente indicativa de uma superação da ciência, tomada como dualidade entre cognoscente e cognoscível, no que diz respeito à apreensão da unidade absoluta do Primeiro Princípio. De outro, b) a dualidade imanente entre Intelecto/inteligíveis, constituinte estrutural uno-múltipla (hén-pollâ) do Intelecto, não permite abordarmos o conhecimento como identidade pura e simples, caso assumamos a perspectiva comparativa com o Uno ${ }^{14}$.

Em outras palavras, é necessário pensar em que condições podemos compreender o sentido autêntico do que chamamos de verdade ${ }^{15}$. E é nessa instauração de condições de possibilidade (compreendida como identidade entre Noûs e nóêta) que as objeções céticas tanto com relação conhecimento sensível (V 5 [32]) quanto com relação à impossibilidade de conhecimento de si (V 3 [49]) exercem um papel definitivo ${ }^{16}$. 


\section{4}

b) Os argumentos céticos e o Intelecto aristotélico.

5. Plotino critica a dualidade existente no Intelecto aristotélico, compreendido cmo "intelecção da intelecção" (nóêsis noêseôs) ${ }^{17}$, pois, segundo ele, não pode ser princípio, uma vez que supõe o que pensa e o que é pensado. Se o Intelecto divino tem como "objeto" de pensamento somente a si próprio, voltando-se para si como ato puro, ainda assim, segundo Plotino, a dualidade é mantida. Ou seja, o Intelecto é ato puro (enérgeia), mas que supõe uma volta para si mesmo ${ }^{18}$. Esse argumento plotiniano contra Aristóteles é semelhante àquele argumento, presente na passagem do Adversus Mathematicos (VII, 310), que aponta para a impossibilidade de conhecimento de si. Tal argumentação reaparece no tratado 49, no interior da discussão sobre o "conhece-te a ti mesmo"19.

O argumento cético é que há dois modos de se compreender a noção de "autoconhecimento": a) nunca pode haver autêntico conhecimento de si, pois isso supõe que aquele que se conhece, conhece como todo, portanto não pode haver conhecimento em sentido próprio. Em outro sentido, b) pode-se considerar ainda que se há uma parte que conhece e outra que é conhecida, portanto sempre haverá uma dualidade entre cognoscente e conhecido, jamais sendo possível um conhecimento de si enquanto tal. Nunca alguém se conhece a si mesmo, pois há sempre uma parte de seu ser que conhece e outra que é conhecida. O voltar-se do intelecto para si mesmo não suprime a dualidade, ainda que consideremos apenas o plano noético. Este argumento é, pois, similar àquele empregado por Plotino contra Aristóteles e, dada sua presença no referido tratado 49, não podemos ignorar a hipótese da grande possibilidade de que Plotino tenha efetivamente tomado o argumento cético para dirigilo a Aristóteles ${ }^{20}$. Plotino não apenas conhece a estratégia cética de crítica à noção de conhecimento de si, mas mobilizando argumentos contra ela, pensa na relação do pensamento como unidade consigo mesmo (cf. V 3 [49], 5, 3.6; 6, 7; 6, 27; 6, 33: o Intelecto é necessariamente acompanhado do conhecimento de si (noûs estin anágkê syneinai autô tên gnôsin heautou); 8, 22.37; 41, 10). Ele dirige sua crítica à noção cética do conhecimento dado parte por parte no Intelecto: "Contendo os entes (ónta), o Intelecto vê a si mesmo (hóron heautòn) e, na medida em que atua, tornase ato (enérgeia), pois o Intelecto e a intelecção são um (hén)" (cf.V 3 [49], $6,5-7)$. Esse voltar-se do Intelecto para si como puro ato remete-nos 
imediatamente ao Intelecto aristotélico. Mas a dialética da uni-multiplicidade que o Intelecto conserva, não permitirá que nele nos fixemos na busca do Princípio ${ }^{21}$.

A presença cética é, de qualquer modo, ainda mais penetrante, e seus efeitos vão muito além de uma mera constatação crítica a seu respeito, da parte de Plotino. Se compreendermos que a crítica plotiniana aos argumentos céticos contra a possibilidade de conhecimento de si possui uma estrutura que impede a divisão do Intelecto, então podemos assumir que tal crítica seja aplicada, no mínimo com a mesma estrutura da crítica cética, igualmente contra Aristóteles. Com efeito, devemos compreender a resposta plotiniana às objeções céticas contra o conhecimento de si da seguinte maneira: a) O Intelecto não pode ser divido em partes, pois isto representaria uma espacialização do inteligível. Compreender o Intelecto partes extra parte seria justamente compreendê-lo segundo uma estrutura temporal, mas precisamente é tal estrutura que caracteriza a Alma voltada para o sensível (cf. III 7 [45]), jamais o Intelecto ${ }^{22}$; b) O Intelecto é idêntico a si mesmo na medida em que podemos postular uma identidade entre inteligência e inteligível. Isso significa que podemos compreender tal crítica da seguinte maneira: Se tomarmos o conhecimento no nível intelectivo a partir de uma estrutura bipolar (cognoscente e conhecido/intelecto e inteligíveis), então estaremos dividindo o Intelecto em partes. Mas não se trata de tomar o Intelecto em seus objetos de conhecimento, mas em seus atos. Ou seja, não podemos deixar de dar assentimento à crítica cética se tomarmos o Intelecto enquanto todo ou enquanto estrutura dual de conhecimento, que cinde cognoscente e conhecido em uma estrutura externa um ao outro, a partir da lógica da relação (são precisas, a esse respeito, as observações de KÜHN, art. cit., p. 242-248; 259-266). Contudo isto nunca pode acontecer dada a natureza interna do Intelecto, pois nele não podermos introjetar uma estrutura temporal (do tipo enquanto...enquanto). O que é conhecido é da mesma natureza daquele que conhece. A alteridade do cognoscente e do conhecido é a alteridade de duas partes ou dois pólos, ou ainda, a alteridade existente entre o conjunto e suas partes (cf.V 3 [49], 5, 10-15).

6. Daí decorre que se tomarmos o Intelecto em seus atos e não nos objetos do pensamento, o Intelecto será múltiplo apenas enquanto supõe uma estrutura dupla em seus atos. Em outras palavras, o objeto inteligí- 


\section{6}

vel e o intelecto são o mesmo, apenas havendo alteração na perspectiva como identidade e como diferença, mas o ato puro do Intelecto é uno. Ora, apenas podemos compreender a estrura uno-múltipla (hén-pollá) do Intelecto na medida em que o tomamos como pura atualidade. $\mathrm{O}$ ato cognitivo (o que é da natureza mesma do Intelecto) e o que é conhecido são o mesmo.

Devemos considerar esta crítica ao ceticismo como um tipo de objeção ao modo de conhecimento que externaliza o sujeito que conhece com relação àquilo que é conhecido. Mas não podemos abandonar a dualidade existente no Intelecto, pois, caso contrário, a crítica de Plotino ao Intelecto Primeiro de Aristóteles estaria comprometida. Há conhecimento de si (crítica aos céticos, tal como aparece no capítulo 5 do tratado 49), mas há desdobramento (crítica a Aristóteles, tal como aparece nos capítulos 10 e 11 do mesmo tratado). De modo que o Intelecto, tomado como totalmente unificado, de um ponto de vista, torna-se cindido de outro. Tal ambigüidade deriva do interlocutor (lá os céticos, aqui Aristóteles) com o qual Plotino dialoga. Essa variação de perspectiva e essa ambigüidade são essenciais se quisermos compreender a múltipla forma pela qual os argumentos céticos são empregados no referido tratado.

Deste modo, temos que considerar que Plotino assume dois pontos de vista diferentes, isto é, do ponto de vista do Uno, o Intelecto é desdobramento: "o intelecto é múltiplo quando quer pensar o princípio que está além (epékeina)" (V 3 [49], 11, 1); do ponto de vista da Alma, o Intelecto é unidade. Por isso é dito "uno-múltiplo" (hén-pollá), nunca "uno" (hén), nem "uno e múltiplo" (hén kai pollâ). Em outras palavras, tais variações de perspectiva dependem da posição na estrutura do universo inteligível que é tomada como ponto de partida para a análise, ou seja, se consideramos as determinações de uma realidade em um nível inferior ou em um nível superior de tal arquitetônica do inteligível. Aliás, TROUILLARD (1961, p. 432-434), foi quem chamou a atenção para tal dialética entre hyper e pro no movimento interno no qual Plotino aborda as possibilidades de assumir diferentes perspectivas no que diz respeito às relações entre inteligível e sensível23.

Logo, no que diz respeito a esse primeiro ponto em que o ceticismo está presente nos textos plotinianos, pa rece haver uma ambigüidade 
essencial com relação ao modo como Plotino se vale dos argumentos céticos, tanto como estratégia crítica, quanto como crítica ao próprio ceticismo. Nesse sentido, estamos diante de uma questão metodológica, como já observmos, que diz respeito à maneira com a qual Plotino emprega determinados argumentos céticos no interior de seu discurso tético. Há uma combinação entre crítica cética e a afirmação de teses, que resulta naquela referida ambigüidade. Em outras palavras, a relevância de tais argumentos pode ser pensada como um "momento do negativo", fundamental na construção do discurso filosófico.

\section{A propósito da inefabilidade do Princípio e da impossibilidade do discurso.}

7. Uma hipótese levantada por alguns comentadores ${ }^{24}$ é que o ceticismo estará presente, ainda, no discurso sobre a inefabilidade do Uno, a fim de resolver problemas provocados pela necessidade de pensar e dizer aquilo que está "além da essência" (epékeina tês ousías). Falamos de nós mesmos ao falarmos do Uno, ou seja, falamos do Princípio a partir da multiplicidade em que estamos mergulhados, isto é, o perfeito e ilimitado é expre sso a partir do imperfeito e limitado (cf.VI 9 [9], 3, 49-54). Falando do Uno como "causa primeira", por exemplo, exprimimos apenas nossas afecções (pathê) que refletem a contingência de nossa condição, evocando um fundamento último, um primeiro princípio que não somos.

Há uma distinção, feita por O’MEARA (2003, p. 98-102) relativa a um ponto nodal do emprego dos argumentos céticos em relação à inefabilidade do Uno. Trata-se da distinção entre falar das coisas e falar das coisas como modo de falar do Uno, em um sentido, portanto, indicatiwo. Sem isso, segundo O’Meara, recairíamos em uma enorme confusão conceitual, sobretudo diluindo a distinção entre o Uno e o que dele procede. Tal distinção remete-se, de um lado, ao fato de que falar das coisas como modo de falar do Uno é especificamente referir-se a um discurso que ressalta a dependência das coisas com relação ao Princípio. Podemos dizer que nossa dependência com relação a algo que está além de nós mesmos é sua presença em nós, sendo dessa presença que falamos ao falarmos do Uno. O’Meara argumenta que Plotino encontra tal a idéia segundo a 


\section{8}

qual apenas falamos de nossas afecções em Sexto Empírico: "Mas o essencial é que, enunciando tais expressões, ele diz aquilo que lhe aparece e se relaciona com seu próprio afeto (to páthos apaggállei to heautou), sem sustentar opiniões, nada assegurando acerca do que lhe é exterior (tôn exôthen hypokeiménôn)" 25 . O cético não pretende dizer as coisas enquanto tais, mas limita-se a falar daquilo que apare ce. O que causa a afecção permanece além (epékeina) da possibilidade de conhecimento. A estrutura do discurso cético fornece, portanto, a Plotino uma solução lhe que permite preservar a negatividade radical do conhecimento do Uno, que parmanece inefável. O’Meara nota, ainda, duas diferença principais entre o discurso cético e o plotiniano. A primeira é que há uma distância entre a incognoscibilidade absoluta do Uno plotiniano e a incognoscibilidade provisória da coisa para o cético. Em segundo lugar, o cético limita a significação de seu discurso à pessoa e ao momento da experiência que ele enuncia. As afecções expressas pelo cético não ultrapassam, em sua significação, o indivíduo que as exprime em um determinando momento por meio de um ato perceptivo. A expressão de algo é a expressão de seu modo de ser dado no devir, reduzida ao indivíduo a quem aparece e que é sujeito da expressão (O’MEARA, 2003, p. 100-101). De outro lado, para Plotino tais afecções reportam-se a outra coisa, para além da própria afecção, ou seja, nossa contingência e precariedade exprimem algo diferente de nossa própria contingência, a afecção é sempre afecção de algo externo, indicando uma possibilidade de conhecimento, embora precário (cf.V 3 [49], 14, 5-13).

Cabe insistir, nesse contexto, no primeiro aspecto, porém ressaltando a prática cética no interior do discurso plotiniano que circunscreve não o falar das coisas como um modo de falar do Uno, ao contrário, o discurso cético denota um dos modos de falar da inefabilidade do Princípio, ressaltando-a. Trata-se de uma das estratégicas para indicar o estatuto incognoscível do Uno. O que resta da prática cética é que o efeito da crítica de nosso conhecimento sensível ou discursivo, demarcando sua insuficiência estrutural, tal como já vimos ao abordarmos a relação entre unidade e multiplicidade do conhecimento. Tais efeitos permanecem ainda que consideramos que apesar de jamais podermos dizer o que é o Uno enquanto tal, podemos apreender, na ordem do múltiplo para os diversos graus de unidade, os traços (ikhnê) do Uno. 
O problema que se coloca aqui é se dizemos certas afeç̧ões nossas que se referem a Ele. Em outras palavras, se nossas afecções podem ter o papel de indicar algo do Uno ou se elas são, de tal modo, exterioridade, de maneira que mesmo que consideremos que não falamos senão a partir daquilo que nossas afecções nos indicam, nunca poderemos falar diretamente do Uno, predicar sua natureza, nem sequer de modo indicativo. Nesse contexto, o "além” (epékeina) é signo de uma transcendência, mas igualmente de limitação e impossibilidade, denotando os limites de nossa percepção e de nossa linguagem. Parece haver uma impossibilidade estrutural no que diz respeito às afecções como elemento que indicaria um modo de falar do Uno. Na verdade, se Plotino encontra nas Hypotyposes um discurso pelo qual ele pode comentar a negatividade absoluta do Uno para nós, de outro lado, p a rece ser necessário observar que igualmente está consciente das aporias implicadas em tal discurso. Tal aporética diz respeito à relação entre o continente e o conteúdo das afecções, ou seja, como as afecções, que são da ordem do sensível e do derivado, podem indicar algo da ordem do inteligível e absolutamente simples, o UnoBem?26 Recordemos que, para o tipo de discurso cético há pouco referido, permanece a impossibilidade de compreensão do conteúdo do que é o "em si" dos objetos que causaram as afecções. Se devo orientar-me com aquilo que aparece à minha percepção e não com as coisas enquanto tais, então, de qualquer modo, estou diante de uma dificuldade incontornável no discurso sobre o Princípio ${ }^{27}$, pois insistir no caráter indicativo das afecções significa uma regressio ad infinitum. O eixo da interpretação de O’Meara, neste ponto, pode ser desviado para a consideração da aporética da determinação do caráter referencial das afecções.

8. Desviando nosso olhar da plausibilidade da relação entre tais textos referidos de Plotino (a respeito de tal relação entre a referência do discurso e afecções) e os textos das Hypotyposes no que tange à inefabilidade do Uno, devemos considerar a ambigüidade presente em tal discurso, da qual Plotino parece valer-se. E é desse ponto de vista que podemos, novamente, ressaltar a perspectiva cética no interior da metodologia plotiniana, agora relativa ao caráter não proposicional da apreensão do Uno. Nos capítulos 5 e 6 do tratado 9 encontramos exe mplos do modo pelo qual aquilo que é dito sobre o Uno pode ser interpretado como se relacionando àquilo que, de fato, é dependente dele. 


\section{0}

Por exemplo, o Princípio não pode ser descrito como "bom”, pois essa palavra é relativa, referindo-se a uma falta ou a um sentido específico no qual aplicamos o termo "bom" (isso é bom para ele, ou é bom neste ou naquele sentido). Tal designação (o Uno como Bem) exprime nossa própria falta de auto-suficiência com relação àquilo que é causa absolutamente primeira, que se basta a si mesma, sem qualquer carência (cf.VI 9 [9], 6, 34-42). Adotamos esses conceitos procurando conduzir a inteligência a uma certa unidade de sentido, elaborando uma noção daquilo que supera nossa dispersão no múltiplo ${ }^{28}$.

A dependência que há em nós e nas coisas que nos envolvem é a presença do Uno em nós e no mundo, sendo disso que falamos ao falarmos do Uno. Assim, Plotino procura evitar a contradição, sustentando que o Uno é inefável, e afirmando diversas coisas do Uno. O discurso sobre o Uno deve preservar sua inefabilidade ${ }^{29}$. Falar do Uno é falar a propósito dele, isto é, falar de nós mesmos e de outros aspectos do mundo, que podem ser ditos na medida em que manifestam uma dependência, uma deficiência ou uma carência com relação a algo que é anterior ou superior a ela. Admitindo que essa abordagem salva gua rda a inefabilidade do Uno, podemos perguntar se o preço a ser pago não é muito alto. Se, falando do Uno, falamos daquilo que procede dele, em que sentido falamos realmente do Uno? O mesmo texto do tratado 49 parece indicar tal dificuldade, mas na encruzilhada entre a suspensão sistemática do juízo e a afirmação da limitação de nossa linguagem a respeito do Uno, Plotino insiste na possibilidade de identificar um Princípio supremo, ainda que inefável. Mas por quê? Não por uma espécie de versão avant la léttre do credo quia absurdum, mas pela possibilidade da ascensão intelectual à Unidade Primeira, indicada como epékeina tês ousías. Daí a afirmação da possibilidade de um modo de conhecimento supra-noético pela via da assimilação (homóiosis), da inteligência unitiva (synesis), da presença (parousía), do tocar (thiggánein) da visão (théa) ${ }^{30}$. Isso supõe a simplificação máxima do intelecto, sua unificação (hénosis), pois "o semelhante se conhece pelo semelhante". Eis a via de mão dupla do ceticismo ao platonismo de Plotino.

$\mathrm{Na}$ estrutura essencialmente dual do conhecimento provindo da afecção há uma limitação. A afecção diz respeito a algo esscialmente outro, externo, o qual nosso intelecto não pode relacionar à transcendên- 
cia absoluta do Primeiro Princípio, absolutamente simples (haplos). Ora, se a referência crítica de Plotino com relação a tal dualidade é dada pelos termos "externo" (exô) e "outro" (hetherôs), entrelaçados em tal contexto argumentativo, como poderíamos conceber o discurso provindo das afecções como um modo, ainda que indicativo de falar do Uno? Da presença do Uno não podemos falar pela via da afecção, mas daquela absoluta autoposição do Intelecto cujo ato cognitivo conhece-se a si mesmo, tal como é apresentada na refutação plotiniana da crítica cética à possibilidade de conheciemento de si no Intelecto ${ }^{31}$. A fidelidade ao princípio da inefabilidade não nos conduz a renunciar a todo e qualquer discurso? O silêncio decorrente deste percurso não é senão a máxima simplificação e unificação (hénosis) do intelecto nos limites do inteligível ${ }^{32}$, uma vez que o Princípio permanece inefável (árrêtos) ${ }^{33}$.

Não pode haver exterioridade nem dualidade (VI 9 [9], 11, 5), mas uma unidade, cujo vínculo é a imagem da visão imediata $(9,11,6$ : "o contemplante e o contemplado formavam umaunidade, como se o contemplante estivesse unido àquilo que via, a rememoração seria daquilo em que havia se tornado quando estava unido a ele [ao Uno], conservando em si mesmo sua imagem" $)^{34}$. Como já foi notado no capítulo 10 do mesmo tratado (10,9-13), no que tange à contemplação, não há dualidade entre aquele que vê e aquilo que é visto. Ocorre uma espécie de mimese do intelecto daquele que investiga com relação ao Intelecto, em sua apreensão do Uno, ou seja, ele permanence na uni-multiplicidade, mas buscando um nível máximo de conhecimento da unidade. Isso implica no voltar-se do intelecto para si, que se reflete no voltar-se do sábio para a sua interioridade. Além disso, cabe notar que tal modo de falar inscreve-se num contexto investigativo particular. Estamos longe do termo de tal itinerário filosófico, qual seja, a apreensão do Uno ${ }^{35}$. Eis por que, após essa espécie de "transfiguração" ("aquilo em que havia se tornado quando estava unido a ele [ao Uno]") o contemplante guarda disso uma imagem ou uma recordação mais ou menos precisa. É a partir desse tipo de recordação (anámnesis) que ele poderá discorrer, ainda que apenas empregando um variegado de imagens, que apenas indicariam ao filósofo o caminho a seguir no curso da contemplação, e, a fortiori, encontrando simultaneamente seus limites.Trata-se, portanto, de um discurso aporético: limitado e limitador. Plotino designa esse tipo de discurso no final do tratado 9, como 


\section{2}

um discurso audacioso, temerário, extremo (hó tolmêròs logos:VI 9 [9], 10, 13), aquele que pretende ser uma expressão da apreensão da verdade no inteligível. E no capítulo conclusivo do tratado (VI 9 [9], 11, 23-24), em linhas que estejam talvez dentre as mais tensas e densas investigações relativas às apreensão do Uno, há um jogo com expressões paradoxais, mutuamente restrtitivas e complementares simultaneamente (ekstásis kai háplôsis kaì epídosis... kai éphesis pros haphên kaì stásis kaì perinóêsis prós epharmogên: êxtase, simplificação, plenitude, desejo de ver, quietude, pensar que visa a união). Elas denotam, em seus contrastes e complementos recíprocos, o deslocamento e a ambigüidade do tolmêròs lógos.

\section{Observações Conclusivas}

Se quisermos retomar aquela afirmação de Arnou citada no início, podemos considerar que o pensamento plotiniano, em suas relações com a argumentação cética tout court, nas múltiplas variações de pers pectiva em que ela aparece nas Enéadas, é essencialmente um pensamento da ambigüidade. A variação de perspectiva e a ambigüidade provindas das diferenças entre os interlocutores (os céticos ou Aristóteles, como vimos) com os quais Plotino dialoga, exigindo uma dinâmica crítica do filosofar, levam-nos a crer que estamos, considerando o procedimento interno à constituição dos tratados plotinianos, próximos do procedimento dos diálogos platônicos ${ }^{36}$. Aqui muitas perspectivas investigativas parecem estar abertas na verificação de um conteúdo dialético platônico interno à diatribe plotiniana ${ }^{37}$.

Há uma porosidade entre ceticismo e o platonismo plotiniano maior do que, à primeira vista, se pode supor, que influencia seu modus operandi nas diversas direções para as quais se dirige sua reflexão crítica, ainda que consideremos que o resultado será um reencontro dinâmico e fértil do platonismo. Embora sendo um precursor de Agostinho e Descartes, a preocupação plotiniana não é, nesse sentido, similar à cartesiana, na qual o emprego arsenal cético resulta na certeza do Cogito, princípio primeiro para uma filosofia positiva e sistemática. Ou seja, a suspensão do juízo sobre o mundo exterior não se converte em“estratégia-padrão" e em componente metodológica à positividade sistemática ${ }^{38}$. 
No itinerário plotiniano, diferentemente, é a negatividade absoluta do Primeiro Princípio “além da essência” (epékeina tês ousías) que escoa sem cessar para o interior da "estrutura" do universo inteligível ${ }^{39}$. Não será precisamente uma certeza sistemática que o pensamento plotiniano colherá dos argumentos céticos, mas uma espécie de dynamis da negatividade. Se ele assume um dogmatismo de tipo platônico, não se constrói senão de modo essencialmente dialético. Não se trata de começar por postular, ab initio, algum princípio, ou seja, instituí-lo a priori, sem qualquer processo investigatio e repleto de dúvidas. Há, portanto, uma fissura na inteligibilidade transparente do todo, que impõe uma outra ambigüidade na relação entre Plotino e o ceticismo, pois tanto a mudança de perspectiva quanto o recuo ocasionado pela crítica cética, nas instâncias que indicamos, apontam para um limite intransponível do conhecimento quando voltamo-nos para o Princípio. Ele permanece como um contorno obscuro em relação àquilo que podemos dizer dos princípios inteligíveis, o Intelecto e a Alma. Essa negatividade no modo de conhecimento do Princípio pode ser um caminho para questionarmos a adequação da atribuição da noção de sistema para a filosofia plotiniana, se compreendermos sistema como uma totalidade fechada, articulada pela unidade da idéia. Ainda que pudéssemos nos remeter à noção de systema, em seu sentido estóico, ou seja, como uma totalidade permeada pelo lógos, a estrutura do mundo inteligível plotiniano estaria ainda comprometida por aquela negatividade. Novamente, é ao platonismo, em suas fontes primevas, que devemos remontar. A reflexão sobre os princípios, da qual o ceticismo é um momento que exerce o "trabalho do negativo", compõe um dos prismas da metodologia plotiniana, impondo-lhe uma de suas tensões constitutivas.

1 Sobre o problema do enquadramento de Plotino na "luta pela ortodoxia" presente na tradição platônica, cf.ATHANASSIADI, 2006.

2 E. BRÉHIER, 1991, tomo V, p. 37-38, 40, 83 e 85; tomo VI, 2, p. 194.

3 Destacamos os estudos que abordam diretamente a temática: WALLIS, 1987, p. 911-954: estudo sugestivo e inovador, que ilumina inúmeras referências implícitas sobre as objeções céticas quanto ao conhecimento sensível, quanto ao conhecimento de si, notadamente em V

doispontos, Curitiba, São Carlos, vol. 4, n. 2, p.247-273, outubro, 2007 


\section{4}

3 [49], bem como a relação entre ceticismo e inefabilidade do Uno, na parte final do artigo. O estudo será seguido, ao menos quanto à sua estrutura, pelos trabalhos de CRYSTAL, 1998, p. 265-286; O'MEARA, 2003, p. 91-98 (tratando, em sua segunda parte, particularmente a problemática da relação entre ceticismo e a inefabilidade do Uno). É penetrante a análise de KÜHN, 2003, p. 229-266, com relação à estrutura do argumento plotiniano contra a crítica cética do conhecimento de si, tomado a partir do esquema da alteridade, presente na lógica da relação entre todo e parte no Intelecto, e criticando as interpretações de Szlezák, W. Beierwaltes e B. Ham (cf. abaixo). Além desses estudos, referências várias aos argumentos de Sexto Empírico ao longo da discussão de questões particulares encontram-se em SZLEZÁK, 1979, particularmente, capítulos. 2 e 3; BEIERWALTES, 1991; 2003, p. 11-39, cujas p. 15-19 referem-se diretamente ao pro blema do conhecimento de si, levando em conta os argumentos céticos contra tal possibilidade, texto retomado em BEIERWALTES, 2001, p. 84-122; particularmente a parte II, 1: Tò autò eautó - "selbst sich selbst" - autô eautón - "durch sich selbst sich selbst". Für die Möglichkeit von "Selbsterkenntnis" gegen deren Bestreitung durch Sextus Empiricus, p. 88-94, revisa as teses de Selbsterkenntnis und Erfahrung der Einheit (cf. supra), sobretudo no que diz respeito à noção de "experiência (Erfahrung) da unidade" no plano do Intelecto, no quadro da identificação da crítica plotiniana às objeções céticas com relação ao conhecimento de si; outras traduções e comentários do tratado 49: OOSTHOUT, 1991, e ainda o comentário recente de HAM, 2000, notadamente o comentário sobre o conhecimento de si do Intelecto, p. 131-141; sobre a relação do Intelecto consigo mesmo, tomado a partir da imagem do "Intelecto amante", PERCZEL, 1997, p. 223-264 (discutido por BAIERWALTES, 2001, p. 88 seg.); particularmente sobre o pro blema do conhecimento sensível e sua possibilidade, a partir do exame da metáfora do mensageiro presente no tratado 49, com relação ao conhecimento sensível, cf. MOREL, 2003, p. 209-227; mitigando em sua estrutura fundamental o argumento segundo o qual Plotino teria considerado ou empregado argumentos céticos contra o conhecimento sensível, EMILSSON, 1996, p. 217-249; cf. a exposição e revisão da questão feita por esse autor em seu notável trabalho recente, Plotinus on Intellect, 2007, p. 141-152; RAPPE, 2003, p. 250-274; SANTA CRUZ, 2006, p. 59-73, particularmente, p. 62-65; BUSSANICH, 1988; vale ainda mencionar um texto penetrante, mas constantemente esquecido de TROUILLARD, 1965, p. 59-75.

${ }^{4}$ A grafia Noûs refere-se ao Intelecto, considerado por Plotino como hipóstase, ou seja, a realidade que constitui um aspecto da realidade que contém a totalidade dos inteligíveis. Ele é o primeiro nível de desdobramento e multiplicidade que procede do Primeiro Princípio, o Uno. Quando houver a grafia noûs, trata-se do intelecto humano em particular, de cada homem singular. Por vezes, ressaltamos essa diferença, dizendo "Intelecto-hipóstase".

5 Acerca do Princípio da Anterioridade do Simples, particularmente com relação ao Intelecto, cf. D. O'MEARA, 2004, p. 51-60; 1990, p. 145-156; 2003, p. 98-103.

${ }^{6}$ Que compõem a grande obra formada por III 8 [30];V 8 [31];V 5 [32]; II 9 [33]. Para uma crítica a tal perspectiva de leitura conjunta da sequêencia de tais tratados, ATHANASSIADI, 2006, p. 123-125.

7 Cf., a esse respeito, BEIERWALTES, 2001, p. 30-34; particularmente sobre a compreensão da unidade do pensamento, p. 43-44.

8 Cf. O'MEARA, 2003, p. 92-97; MOREL, 2003, p. 210-211.

doispontos, Curitiba, São Carlos, vol. 4, n. 2, p.247-273, outubro, 2007 
${ }^{9}$ Recorde-se a apologia de Protágoras no Teeteto, $166 \mathrm{c}$ seg.

10 Cf. ainda IV 6 [41], 30-32; cf. SEXTO EMPÍRICO, Hypot., II, 51; II, 74-75; Adv. Math. VII, 357-358; 384-385; cf. O’MEARA, ibid.

11 Cf. BEIERWALTES, 2003, p. 20-28; 2001, p. 90 seg; KÜHN, 2003, p. 252-260.

12 Cf. D. O’MEARA, 2003, p. 97.

13 Cf.ABBATE, 2003, p. 625-678; D’ANCONA COSTA, 1990, p. 437-474; 1992, p. 69-113; CRYSTAL, 1998, p. 283-286.

14 Sobre o pro blema da pura atualidade do Intelecto, em perspectiva aristotélica, e a crítica plotiniana, AUBRY, 2006, particularmente, p. 223-239.

15 Neste ponto, não parece ser inadequado observarmos a similaridade com o procedimento que, posteriormente, filósofos como Descartes irão adotar na construção de sua filosofia. A dúvida metódica cartesiana, tal como aparece na $1^{\mathrm{a}}$. Meditação, pretende valer-se de diversos argumentos que podem ser mobilizados contra as bases do conhecimento possível (sentidos, imaginação, valor objetivo das essências matemáticas), afirmando-se finalmente a partir dos elementos que resistem à dúvida, por sua evidência e indubitabilidade (como ocorrerá na $2^{\mathrm{a}}$. Meditação, no encontro indubitável do Cogito [parágrafos 4-9] e na identificação do primado do intelecto, ilustrado pelo argumento do pedaço de cera [parágrafos 10-18]). Mas aqui este paralelo encontra seus limites intransponíveis, pois onde Descartes chega após a aplicação da dúvida é a um tipo de dogmatismo sistemático, que supõe a certeza do Cogito, na qual o sujeito do conhecimento como ponto de partida, bem diverso daquele plotiniano. Sobre Plotino e Descartes, com particular atenção à pro blemática do conhecimento sensível, discutindo as teses de EMILSSON (1996) cf. DILLON, 1991, p. 165-179.

16 Cf.V 3 [49], 5, 21-48. P recisamente por tal articulação é que, com O'Meara, podemos insistir, contra EMILSSON, 1996, p. 240-241, na relevância do ceticismo neste quadro analítico do tratado 49, cuja ressonância leva aos limites do conhecimento sensível e do discurso sobre o Princípio. Além disso, nesse contexto, a metafórica da luz, lida no contexto exegético da analogia solar é representativa para abordar tal relação entre noêta e Noûs. A metáfora solar é uma via para ilustrar dois aspectos de tal relação entre o Uno e o No ûs, pois a multiplicidade dos entes inteligíveis deriva do Primeiro Princípio, ainda que o Uno-Bem permaneça, em si mesmo, absolutamente simples e uno. Ao mesmo tempo, é do Uno que a totalidade dos inteligíveis - o uno-múltiplo (hén-pollâ) - encontra o fundamento originário de sua própria unidade. No tratado VI 7 [38], 16, 24s, é dito o Princípio Primeiro, tal como o sol, é causa da ousía e do Noûs, luz para o pensado (ou seja, os objetos inteligíveis) e o pensante, isto é, o noûs (phôs kata to analogon tois ekei horatois kai tó horónti). Não sendo nem inteligível (noêta) nem Intelecto (Noûs), o Uno é causa das realidades inteligíveis em seu complexo, ou seja, causa fornecedora, por sua potência de unidade, da unidade do Nốs que contém em si os noêta singulares. Graças à própria "luz" do Uno, se tomado como paradigma de unificação, a realidade inteligível torna-se pensável. Sendo "além da essência" (epékeina tês ousías [República, 509b9]), ele fornece condições de possibilidade de inteligibilidade dos entes inteligíveis que compõem o inteligível enquanto tal, isto é, o Intelectohipóstase. Estruturalmente, o Intelecto deve sua unidade a um critério anterior a si, mantendo-se na dualidade do "em si", na qual há o pensamento de si, e "pelo Uno". Assim, o

doispontos, Curitiba, São Carlos, vol. 4, n. 2, p.247-273, outubro, 2007 


\section{6}

Intelecto é "em si" e "para si", na medida em que nele as categorias de "pensável” e "pensante" supõem desdobramento interno, ainda que num nível mínimo, primeiro. Com relação a este tipo de desdobramento, a sensação será um desdobramento máximo e último. Cf. III 8 [30], 9, 39-40; V 3 [49], 11, 19. A esse respeito, ver CRYSTAL, ibid., p. 282-285. Cf., sobre a metafísica da luz, BEIERWALTES, 1961, p. 334-362 e ABBATE, 2003, p. 652 seg.; Selbsterkenntnis und Erfahrung der Einheit, p. 152 seg.; ARNOU, 1967, p. 256 seg; ver, ainda, ressaltando os paradoxos do capítulo 5 do tratado 49, EMILSSON, 2007 (The puzzles of Ennead V. 3. 5: Self-Thinking Revisited), p. 144- 152; sobrea metáfora da luz em Platão, ver LEBRUN, 2006, p. 401-403.

17 A referência é o contexto de Metaph., L, 1072b 19-21;26-27.

18 Cf. AUBRY, 2006, p. 234-239.

19 Note-se que é o procedimento exegético de Plotino que opera como chave a dinâmica filosófica. Nesse caso, trata-se da exegese do Alcebíades.

20 Esse procedimento é comum nas Enéadas e compõe a dinâmica de sua estratégia crítica.

${ }^{21}$ Veja-se, discutindo a dialética da recepção do Intelecto aristotélico na articulação do Noûs plotiniano, SZLEZÁK, 1979, cap. 3; cf., ainda, DE KONINCK, 2007, p. 71-81.

22 No contexto da discussão do tratado 45 (Sobre a eternidade e o tempo), o tempo é tomado como vida da Alma (ordem do múltiplo), enquanto que o plano do Intelecto é o da eternidade (ordem da uni-multiplicidade). Cf., sobre o tratado 45, a tradução comentada de BEIERWALTES, 1995.

23 Trouillard comenta: “(...) Sabemos que não é o Uno, em sua transcendência nua que cria os inteligíveis e o pensamento, é a expansão indeterminada e fecunda do Uno que se dá às idéias ao mesmo tempo em que se faz espírito. Possibilidades, normas e essências participam do Uno como imanente ou comunicado, e da tensão, para si mesmo, que ele infunde em cada um" (art. cit., p. 434, grifo nosso). O uso plotiniano dos termos hyper e pro, em diversos contextos nos quais é a negatividade do Uno que está em jogo, para Trouillard, indicam o jogo entre presença e transcendência do Princípio, constitutivo do inteligível.

24 Seguimos particularmente as sugestões analíticas de WALLIS, ant. cit., p. $952-954$ e O'MEARA, 2003, p. $98 \mathrm{seg}$. que tratam desse tema em seus respectivos trabalhos. Mas nossa preocupação no que segue é insistir na possibilidade de pensar o ceticismo como um componente metodológico na dialética negativa (inefável, mas Princípio) pela qual o Primeiro Princípio, o Uno, é abordado.

25 Cf. Hypotyposes, I, 15; 197. Sobre uso plotiniano do verbo apaggellein e suas relações com a teoria aristotélica da percepção, cf. MOREL, art. cit., p. 213; e DILLON, art. cit., p. 167-168.

26 Lemos em VI 9 [9], 3, 49-55: "Dizer que ele [o Uno] é a causa significa predicar um atributo não a ele mesmo, mas a nós, no sentido em que nós possuímos algo dele, que é em si mesmo. Mas aquele que fala com exatidão não diz 'ele' ou 'é', mas giramos em torno a ele, do exterior, por assim dizer, desejando comunicar nossas afecções, por vezes, distanciando-nos, devido aos dilemas em que estamos envolvidos".

27 Sobre essa questão, cf. PORCHAT, 1994, p. 166-212, 176-181.

doispontos, Curitiba, São Carlos, vol. 4, n. 2, p.247-273, outubro, 2007 
28 No capítulo 14 do tratado 49, Plotino fornece uma imagem daquilo que ele entende quando diz que, falando do Uno, falamos de nossas próprias experiências: "Não o possuimos de modo a poder falar a seu respeito, nem mesmo dizê-lo em si mesmo. Dizemos aquilo que ele não é; aquilo que ele é não o dizemos. De modo que é a partir daquilo que é posterior [a ele] que dele falamos. Não estamos impedidos de possuí-lo, ainda que não possamos dizê-lo. Mas como aqueles que são inspirados e tornam-se [divinamente] possuídos, sabem que possuem algo de maior em si mesmos, ainda que não saibam o que, pois são mudos e falam, adquirindo algum sentido daquilo sobre o que calam, sendo diferentes dele, parecem estar, de algum modo, unidos a ele [o Uno]" (V 3 [49], 14, 5-14). O'Meara interpreta essa passagem a partir da referência à argumentação cética a propósito da impossibilidade do conhecimento sensível apreender as coisas em si mesmas, aplicada à inefabilidade do Uno. Ora, há um caráter aporético dado pela ambigüidade entre falar do Uno e falar das coisas como modo de falar do Uno, mas a passagem permite compreender que Plotino encaminha uma alternativa à tal aporética instaurada pelo discurso cético.

29 Cf. HOFFMANN, 1997, p. 335-390, notadamente, p. 340 seg.

30 "E se, uma vez que ele não é nenhuma dessas coisas [i.e, bem, vontade, pensamento, ente, essência], te encontres, em teu pensamento, num estado de indeterminação, detém-te precisamente nessas coisas e, a partir delas, olha. Mas olhe sem projetar teu pensamento para o exterior. Pois ele não está situado em algum lugar, deixando todas as outras coisas privadas de si, mas ele está sempre presente para quem pode tocá-lo, ausente para quem é incapaz" (VI 9 [9], 7, 1-6, sigo a tradução de Hadot). É necessário notar que, ainda no tratado 9 , precisamente em um dos momentos em que o intelecto dirige-se à investigação do que está para além do Intelecto, a "conversão" (epistrophê) e a "purificação" (kátharsis) são postas como exigências para quem quer que queira "filosofar a propósito do Uno" (perì tò hèn philosophêsein:VI 9 [9], 3, 14). Há uma mútua implicação entre o discurso negativo e a exigência de conversão, no continuum da disposição vital daquele que busca e investiga os primeiros princípios da realidade. Aqui encontramos um outro ponto de intersecção entre o discurso crítico a propósito do alcance e dos limites de nossa linguagem e o discurso negativo a respeito do Uno (nos quais a articulação cética está presente). Instaura-se uma circularidade entre a negatividade implícita no percurso aferético em direção ao Princípio e a exigência de "separar tudo" (aphele panta), que aparece no final do tratado 49 (17,38). Tal circula ridade entre essas duas instâncias pode ser considerada na relação interna entre aphairesis (enquanto procedimento intelectual) e kátharsis (enquanto procedimento "moral”). O vocabulário da aphaíresis é central nesse ponto.

31 Cf. supra, primeira parte.

32 R e cordemos a densa passagem do capítulo 3 do tratado 9: "A aporia nasce, sobretudo, porque a apreensão do Uno não pode ser feita nem por meio da ciência (epistêmên), nem por meio da intelecção (nóésis), isto é, da mesma maneira pela qual são conhecidos os outros objetos do pensamento, mas por uma presença que supera a ciência (kata parousian epistêmês kreitona). Pois a alma experimenta um distanciar-se (apóstasin) de sua unidade e não é totalmente una cada vez que ela adquire a ciência de algo: com efeito, a ciência é um discurso racional e o discurso é múltiplo. Desse modo, a alma deixa de ser una, recaindo no número e na multiplicidade. É, portanto, além da ciência (hyper epistêmên) que é preciso se direcionar, não 


\section{8}

abandonando jamais a unidade, mas distanciando-se da ciência e do apreensível pela ciência (epistêtôn) e de qualquer outro objeto de contemplação, mesmo do belo (kaì kalou theámatos). Pois aquilo que é belo é posterior ao Uno, provindo do Uno, como a luz do dia provém do sol. Eis a razão pela qual Platão diz que ele não pode ser expresso pelo discurso nem pela escrita (CartaVII, 341c5), mas se dele falamos ou escrevemos é com a finalidade de conduzirnos para Ele, para encorajar-nos à visão, com o auxílio de nossos discursos, tal como se indicássemos o caminho a alguém que deseja ver algo. Pois o ensinamento não pode conduzir senão à rota e ao caminho (gar tês hodou kai tês poreias hé dídaxis [Rep. 532e3]), mas a visão em si mesma é aquele que deseja ver quem deve realizá-la" (VI 9 [9], 4, 1-15).

33 Cf. WHITTAKER, 1984, p. 303-306, mostra a formação do vocabulário da inefabilidade e sua história na literatura anterior e posterior a Plotino, embora notando que o termo akatonómastos (inominável) não faz parte do vocabulário plotiniano, possivelmente devido a seu cuidado em evitar termos consolidados no vocabulário gnóstico.

34 Tal modo de conhecimento foi interp retado por muitos (como HADOT, 1994, em sua tradução comentada ao tratado 9 , particularmente os comentários às passagens desse tratado citadas acima) a partir do horizonte da noção de "místico". Essa nomenclatura somente poderia ser aplicada a esse contexto plotiniano desde que se insistisse no que essa experiência mística não é, do ponto de vista filosófico. Ora, o ônus do emprego de tal termo parece ser maior do que a solução que ele apresenta. O que ocorre é que estamos no interior do máximo limite da experiência filosófica propriamente dita. Se a filosofia, aqui, culmina em mística, então seria necessário uma teoria da mística que viesse em nosso auxílio. Estamos, a princípio, diante de uma impossibilidade. Ver o notável balanço da questão feito por BRISSON, 2005, p. 61-72; cf., ainda, BUSSANICH, 1994, p. 5183-5213;TROUILLARD, 1961; sobre o conhecimento "supra-noético", cf. SANTA CRUZ, 2006, p. 68-72 e 2003, in fine.

35 Pode-se recordar que esse tipo de procedimento cético, que culmina na afirmação de um Princípio inefável, encontrará uma ve rsão distorcida nas literaturas fideístas posteriores, a partir do século XVI. Mas qualquer paralelo entre o credo quia absurdum e o termo do processo investigativo plotiniano é, como já ressaltamos, inadequado. A presença de argumentos céticos na trajetória do intelecto em direção ao Uno jamais concede ao irracionalismo, mas, ao contrário, é o termo de um processo do próprio nous, que demarca seus limites, bem como os limites da linguagem. E é precisamente aqui que, igualmente, a noção de uma unio m̌stica que suprime a racionalidade é inadequada.

${ }^{36}$ Vale lembrar uma observação de V. Goldschmidt a propósito de Platão, que talvez aponte para algo análogo ao que ocorre com Plotino. Tal analogia justifica a longa citação:"O ensino", diz Goldschmidt, "somente pode ser inscrito numa alma consciênte de sua ignorância, e é por este motivo que, na maior parte de sua obra, Platão antes nos ensina a duvidar das coisas sensiveis que a conhecer as Formas. Nenhum diálogo começa por 'pôr' Deus, o Bem ou as Formas. O platonismo autêntico nunca se ofere ce, de início, o luxo de algum 'princípio' donde se possa deduzir o resto. Ele sempre começa por onde todos começam; todas as investigações se voltam, inicialmente, para as coisas mais familiare do universo em que vivemos; não há nenhuma pesquisa dialética que não tenha sido, no começo, uma simples conversação. E se chega, entretanto, um momento em que a brincadeira se torna dialética, em que se passa das coisas às Formas, é certamente porque não se pode agir de outro modo. A filosofia sempre aparece como uma solução de emergência, em conseqüência de ter uma aporia tornado

doispontos, Curitiba, São Carlos, vol. 4, n. 2, p.247-273, outubro, 2007 
impraticáveis todos os outros caminhos. É somente então, quando, já engajados no caminho dialético, nos tornamos para as sendas batidas, que experimentamos uma ofuscação (Rep. 517d) diante da obscuridade, uma impressão de despertar após um sonho profundo (Rep. 476e; 533b-c), e que se produz uma inversão (Górgias 481c) dos valores, que nos faz depreciar radicalmente o mundo em que vivíamos até então, em favor de uma realidade nova e 'realmente real"'. Além disso, Goldschmidt notava que se o Bem é obscuro, as outras formas não o são menos (GOLDSCHMIDT, 1970, p. 34-35; cf., ainda, as observações de LEBRUN, 2006, p. 400.

37 Tal perspectiva nos aponta para a questão relativa ao resgate plotiniano dos diálogos platônicos de juventude. A esse respeito, cf. TAORMINA, 2000, p.137-196. Além disso, a presença da aporética socrática pode ser discutida se considerarmos a noção de "enigma" (cuja análise não cabe no momento), no contexto metodológico da exegese plotiniana, cujo papel é central na exegese plotiniana, enquanto uma aporia que demanda investigação.

${ }^{38}$ Ver, a esse respeito, O. Porchat. Mundo exterior e ceticismo. In: op. cit., p. 125.

39 No que diz respeito ao desafio cético ao conhecimento, Plotino é um precursor de Agostinho e Descartes em dois aspectos: mobilizar a crítica cética contra as epistemologias externalistas, que postulam a base sensível para o conhecimento, afirmando que verdadeiro conhecimento está no plano inteligível. E, em segundo, lugar, não sendo paralizado pela crítica cética, uma vez que considera que ainda que não tenhamos a certeza do que é o objeto em si mesmo, que originou nossa afecção, de qualquer modo, há uma base para tal percepção. Ou seja, se os sentidos conhecem algo equivocamente, ao menos conhecem "algo", ainda que ele não possa ser determinado. Logo, há algum tipo de conhecimento positivo. Tal como ressalta a conclusão de D. O'Meara, art. cit., p. 102-103; nesse sentido, ainda, talvez possamos inverter o título do artigo de J. Dillon. Plotin, le premier des cartésiens?, questionando: "Descartes, o último dos plotinianos

\section{Referências bibliográficas}

A. Fontes.

1. Plotino:

HENRY, P. e SCHWYZER, H. R. (ed.). 1964-1982. Plotini opera (editio minor). Oxford: Oxford Clarendon Press.

BRÉHIER, É. 1991. Ennéades. Tomos V e VI. Paris: Les Belles Lettres.

IGAL, J. 2001. Enéadas. 3 volumes. Madrid: Gredos.

RADICE, R. 2003. Enneadi. Milano: Mondadori.

HADOT, P. 1987. Traité 38. Paris: Cerf. 
BEIERWALTES, W. 1991. Selbsterkenntnis und Erfahrung der Einheit. Plotins Enneade V 3. Frankfurt am Main:Vittorio Klostermann.

HADOT, P. 1994. Traité 9. Paris: Cerf.

BEIERWALTES, W. 1995. Über Ewigkeit und Zeit (Enneade III 7). Frankfurt am Main:Vittorio Klosterman.

HAM, B. 2000. Traité 49. Paris: Cerf.

2. Outros autores antigos:

PLATÃO. 2005. Teeteto. Introdução, tradução e notas de Adriana Manuela Nogueira e M. Boeri, prefácio de J. Trindade Santos. Lisboa: Calouste Gulbenkian.

ARISTÓTELES. 1998. Metafísica. Ed. trilíngüe. Tradução V. G. Yebra. Madrid: Gredos.

SEXTO EMPÍRICO. 1997. Esquisses pyrrhoniennes. Ed. bilíngüe. Tradução de P. Pellegrin. Paris: Seuil.

-1946. Adversus Mathematicos. Ed. bilíngue. Tradução R. G. Bury.Volumes 2-4. Cambridge/Massachusetts/London: Harvard University Press/W. Hinemann.

B. Estudos.

ABBATE, M. 2003. "Il Bene nell'interpretazione di Plotino e di Proclo”. In: M. VEGETTI (dir.). Platone. La Repubblica.Vol.V, lib.VIVII. Napoli: Bibliopolis, pp. 625-678.

ARNOU, R. 1967. Le désir de Dieu dans la philosophie de Plotin. 2a. ed. Roma: Presses de l'Université Grégorienne.

ATHANASSIADI, P. 2006. La lutte pour l'orthodoxie dans le platonisme tardif. De Numénius à Damascius. Paris: Les Belles Lettres.

AUBRY, G. 2006. Dieu sans la puissance. Dunamis et energeia chez Aristote et Plotin. Paris:Vrin.

BEIERWALTES, W. 1961. "Die Metaphysik des Lichtes in der Philosophie Plotins", Zeitschrift für philosophische Forschung, 15, pp. 334-362. 
. 2001. Das Wahre Selbst. Studien zu Plotins Begriff des Geistes und des Einen. Frankfurt am Main:Vittorio Klostermann.

-2003. "Le vrai soi”. In: DIXSAUT, M. (dir.). La connaissance de soi. Études sur le traité 49 de Plotin. Paris:Vrin, pp. 11-39.

BRISSON, L. 2005. "Peut-on parler d'union mystique chez Plotin?”. In: DIERKENS, A. e RYKE, B. Mystique: la passion de l'Un, de l'Antiquité à nos jours. Bruxelles: Editions de l'Université de Bruxelles, pp. 61-72.

BUSSANICH, J. 1988. The One and its relations to Intellect in Plotinus: a comentary on selected texts. Leiden: Brill. . 1994. "Mystical elements in the thought of Plotinus". In: Aufstieg und Niedergang der Römischen Welt, II, 36-7, pp. 5183-5213. CRYSTAL, I. 1998. "Plotinus on the structure of self-intelection". Phronesis, 43, 3, pp. 265-286.

D’ANCONA COSTA, C. 1990. "Determinazione ed indeterminazione nel sovrasensibile secondo Plotino". Rivista Critica di Storia della Filosofia, 45, 3, pp. 437-474.

-1992. "Amorphon kai aneideon. Causalité des formes et causalité de l'Un chez Plotin". Revue de Philosophie Ancienne, 10, 1, pp. 69-113.

DE KONINCK, T. 2005. "La métaphysique et la question de Dieu chez Aristote”. In: ZARKA, Y. C. e PINCHARD, B. Y a-t-il une histoire de la métaphysique? Paris: PUF, pp. 57-81.

DILLON, J. 1991. "Plotin, le premier des cartésiens?”. Rue Descartes, 1, 2, p. 165-179.

EMILSSON, E. K. 1996. “Cognition and its objects”. In: GERSON, L. (ed.). The Cambridge Companion to Plotinus. Cambridge University Press, pp. 217-249.

2007. Plotinus on Intellect. Oxford: Clarendon Press.

GOLDSCHMIDT,V. 1970. A religião de Platão, São Paulo: Difel. 
HOFFMANN, Ph. 1997. "L'expression de l'indicible dans le néoplatonisme grec de Plotin à Damascius”. In: LÉVY, C. e PERNOT, L. Dire l'evidence. Philosophie et rhétorique antiques. Paris: L'Harmattan, pp. 335-390.

KÜHN, W. 2003. "Comment il ne faut pas expliquer la connaissance de soi-même (Ennéade V 3 [49], 5, 1-17)”. In: DIXSAUT, M. (dir.). Ibid., pp. 229-266.

LEBRUN, G. 2006. "Sombra e luz em Platão". In: A Filosofia e sua história. São Paulo: Cosacnaify, pp. 401-403.

MOREL, P.-M. 2003. "La sensation, messagère de l'âme. Plotin,V 3 [49], 3”. In: DIXSAUT, M. (dir.). Ibid., pp. 209-227.

O’MEARA, D. 2004. Plotin. Une introduction aux Ennéades. Paris/Fribourg: Cerf/Academic Press Fribourg.

- 2003. "Scepticisme et ineffabilité chez Plotin". In: DIXSAUT, M. (dir.). Ibid., pp. 91-103.

-1990. "Le problème du discours sur l'indicible chez Plotin". Revue de Théologie et de Philosophie, 122, pp. 145-156.

OOSTHOUT, H. 1991. Modes of knowledge and the transcendental. An introduction to Plotinus Ennead 5.3 [49]. Amsterdam: Grüner.

PERCZEL, I. 1997. L'intelect amoreux e l'Un qui est. Une doctrine mal connu de Plotin. Revue de Philosophie Ancienne, 15, pp. 223-264.

PORCHAT, O. 1994. "Sobre o que aparece". In: Vida comum e ceticismo. São Paulo: Brasiliense, pp. 166-212, 176-181.

RAPPE, S. 1996. "Self-knowledge and subjectivity in the Enneads". In: GERSON, L. Ibid., pp. 250-274.

SANTA CRUZ, M. I. 2006. "Modos de conocimiento en Plotino". Clássica. Revista Brasileira de Estudos Clássicos, 19, 1, pp. 59-73. Ibid., pp. 73-90. 
SZLEZÁK, Th. 1979. A. Platon und Aristoteles in der Nuslehre Plotins. Basel/Stuttgart: Schwabe Verlag.

TAORMINA, D. P. 2000. "Plotino lettore dei "dialoghi giovanili” di Platone". In: BRANCACCI, A. (dir.). La filosofia in età imperiale. Le scuole e le tradizioni filosofiche. Napoli: Bibliopolis, pp. 137-196.

TROUILLARD, J. 1961. "Valeur critique de la mystique plotinienne". Revue Philosophique de Louvain, 59, pp. 431-444.

- 1965. "Plotin et le moi". In: A.A.V.V. Horizons de la personne. Paris: Les Éditions ouvrières, pp. 59-75.

WALLIS, R. 1987. "Scepticism and Neoplatonism". In: Aufstieg und Niedergang der Römischen Welt, II, 32.2, pp. 911-954.

WITTAKER, J. 1984. "Árrêtos kai akatonómastos". In: Studies in platonism and patristic thought. London, Variorum Reprints, texto XII. 